Marquette University

e-Publications@Marquette

Mechanical Engineering Faculty Research and

Publications

Mechanical Engineering, Department of

$1-1-2013$

\title{
Freehand Sketching for Engineers: A Pilot Study
}

Richard W. Marklin Jr.

Marquette University, richard.marklin@marquette.edu

Jay R. Goldberg

Marquette University, jay.goldberg@marquette.edu

Mark L. Nagurka

Marquette University, mark.nagurka@marquette.edu

Published version. Published as part of the proceedings of the conference, 120th ASEE Annual Conference \& Exposition, 2013. Permalink. (C) 2013 American Society for Engineering Education. Used with permission. 


\section{Freehand Sketching for Engineers: A Pilot Study}

\section{Prof. Richard W Marklin Jr, Marquette University}

Richard Marklin is a Professor of Mechanical and Biomedical Engineering at Marquette University (Milwaukee, WI). and is a Certified Professional Ergonomist. He has had a successful research program in Ergonomics for over 20 years, but he found that students, both undergradute and graduate, do not know how to express their design ideas visually through freehand sketching. This phenomenon is due to the prevalance of Computer Aided Design (CAD) software, which, starting in 1990, supplanted mechanical drafting and freehand sketching skills that were traditional taught to engineering students.

Prof. Marklin developed a short course to teach engineering students how to express their ideas and concepts with quick freehand sketches that require only a pencil (no instruments such as rulers or compasses are required). This course does NOT require visual art talent. He taught the 5-week course twice in Milwaukee (University of WI-Milwaukee and Marquette University) and is teaching the course at the U. of Costa Rica during Jan. and Feb. 2013. He plans to make a commercial grade video of the course and distribute it on YouTube. In addition, he will continue to teach the course at Marquette University because the course is very popular among engineering students.

\section{Dr. Jay R. Goldberg P.E., Marquette University}

JAY GOLDBERG, Ph.D., P.E. is Associate Professor of Biomedical Engineering, Lafferty Professor of Engineering, and Director of the Healthcare Technologies Management Program at Marquette University where he teaches courses involving new product development and design. Before moving into academia, he was director of technology and quality assurance for Milestone Scientific Inc. (Deerfield, IL). Dr. Goldberg is a registered Professional Engineer in Illinois and Wisconsin. In 2012 he received the National Society of Professional Engineers Engineering Education Excellence Award for linking professional practice to engineering education.

\section{Dr. Mark Nagurka, Marquette University}

MARK NAGURKA, Ph.D. is an Associate Professor of Mechanical and Biomedical Engineering and Lafferty Professor of Engineering Pedagogy at Marquette University. He received his B.S. and M.S. in Mechanical Engineering and Applied Mechanics from the University of Pennsylvania and a Ph.D. in Mechanical Engineering from M.I.T. He taught at Carnegie Mellon University before joining Marquette University. His professional interests are in the design of mechanical and electromechanical systems and in engineering education. He is a registered Professional Engineer in Wisconsin and Pennsylvania, a Fellow of the American Society of Mechanical Engineers (ASME), and a former Fulbright Scholar. 


\title{
Freehand Sketching for Engineers: A Pilot Study
}

\begin{abstract}
This paper describes a pilot study to evaluate Freehand Sketching for Engineers, a one credit, five week course taught to undergraduate engineering students. The short-term goal of this course was to improve engineering students' freehand sketching ability and to assess their progress with metrics. The long-term objective (desired learning outcome) of this course is to improve the creativity and innovation of student design projects by enhancing students' ability to visualize their ideas with freehand sketches. The class met two days a week for 75 min per day. Students were taught to draw simple objects such as electrical boxes, with orthographic, isometric, and oblique views on $8 \frac{1}{2} \times 11$ in. sheets of blank paper (no grid lines) and wooden \#2 pencils. No instruments, such as rulers and compasses, were allowed. The course required students to apply what they learned in the classroom and included many examples of hands-on, active and student-centered learning activities.
\end{abstract}

Two assessments were performed to measure whether students improved their ability to freehand sketch. The first involved two outside reviewers (industrial designers) who evaluated each student's sketch of a pipe fitting that was drawn in the first class (pre-test) and a sketch of the same pipe fitting in the eighth class (after 7 hours of instruction - post-test). Sketches were evaluated using a 1 (poor) to 7 (excellent) Likert scale. The second assessment consisted of an evaluation of the final projects, which were a collection of five sketches with different views of an engineered product. Evaluations of the pre- and post-test drawings and the final projects by outside reviewers and positive observations by engineering faculty suggest that this course has the potential to improve students' ability to sketch objects.

This paper discusses details of the course, provides examples of student sketches, and presents results of outside reviewer assessments. It includes suggestions for a more rigorous assessment of the course to determine its potential to improve students' ability to sketch objects.

\section{Background and Literature Review}

Sketching is a perceptual skill, and it enables a student to spatially visualize many ideas during the conceptual stage of a design project. ${ }^{1}$ Research in cognitive psychology and studies of designers point to the importance of drawing in the design process. Sketching is a form of drawing and is important in design because sketching is "visual thinking". ${ }^{2}$ History reveals the impact of visual thinking. The first engineers, such as Leonardo da Vinci, started as artists during the Renaissance. ${ }^{3}$ The drawings of da Vinci reveal the thought process of his designs applied to a variety of fields, and these drawings are considered paragons in the fields of engineering and architecture.

Research has shown that engineering students who sketched early in the design process were able to achieve a higher quality of design outcome than students who used only a mental approach (no sketching). In a study by Schutze et. al. three groups of mechanical engineering students designed a garden grill through concept development based on a set of written instructions. ${ }^{4}$ One group was allowed to sketch ideas without restraint, the second group was 
allowed to sketch up to $50 \%$ completion of the concept, and the third group was not allowed to sketch (solely mental approach). Results showed that the group that was allowed to sketch without restraint produced higher quality concepts (although they required more time to develop the concepts) than the other two groups. In addition, this group rated the design challenge significantly less difficult than did the other two groups.

Other researchers have found that the quantity of brainstormed ideas from sketches drawn during a design project affected the quality of the design outcome. Yang found that a higher quantity of sketches resulted in better design outcomes. ${ }^{5}$ In this study Yang tested whether the quantity of sketched concepts, on blank or dimensioned paper, at the beginning of a project and during the entire project correlated with the quality of the design outcome with undergraduate mechanical engineering students at the California Institute of Technology. Only the total number of sketches correlated positively with the design outcome. The general trend was fewer overall drawings in the beginning, more in the middle, and a drop in the quantity of drawings at the end of the project.

During the 1950s, engineering education in the U.S. was reformed (in response to Sputnik), and the Grinter Report emphasized the importance of graphical expression, including sketching, as a means for creative thinking, spatial visualization, and the ability to convey ideas. ${ }^{6}$ Although the Grinter Report stated the importance of sketching for engineers, the value of visual thinking in an engineering curriculum has been downgraded during the last two decades, particularly since the advent of CAD technology. In many curricula, freehand sketching is no longer taught to undergraduates, despite the benefits quantified in the literature. ${ }^{4,5}$

\section{The Freehand Sketching Course at Marquette University}

In the winter of 2011, Freehand Sketching for Engineers was taught to 22 undergraduate engineering students by a faculty member in mechanical engineering. Students sketched small, simple objects, such as plastic pipe fittings and electrical boxes, with the parallel drawing systems of orthographic, isometric, and oblique views. Students sketched on blank $81 / 2 \times 11$ in. paper with only \#2 wooden pencils. No other instruments, such as rulers and protractors, were used.

This sketching course required students to apply what they learned in the classroom and included many examples of hands-on, active learning. Active learning is an instructional method that engages students in the learning process. In active learning students conduct meaningful learning activities connected to what they are doing. While this definition could include traditional activities such as homework, in the education literature active learning most commonly refers to activities that are introduced in the classroom. The core elements of active learning are activities that engage students. ${ }^{7,8}$ Active learning is often contrasted to the traditional lecture format where students passively receive information from an instructor.

\section{Goal and Desired Learning Outcome of Course}

The short-term goal was to improve engineering students' freehand sketching ability and to assess their progress with metrics. The long-term objective (desired learning outcome) is to enhance the creativity and innovation of engineering students' design projects by improving 
students' ability to freehand sketch. This desired learning outcome supports the Marquette University College of Engineering's goal of increasing the level of active and student-centered learning in the engineering curriculum. ${ }^{8}$

\section{Structure of Course}

This course taught students how to visually communicate their ideas, (objects or thought processes), with nothing more than a pencil and a piece of paper. Students used only a wooden \#2 pencil on blank, white $8 \frac{1}{2} \times 1$ in. paper (no grid lines), and they did not use rulers, $\mathrm{T}$ squares, triangles, or any computer software. Twenty-two undergraduate engineering students enrolled in the 5-week, one credit hour course. The class met two days a week for 75 min per day (10 sessions total). Students sketched geometrically-shaped objects with three parallel drawing systems. These included 1) Orthographic (2D -- front, side, top views), 2) Isometric (3D), and 3) Frontal and Plan Oblique (3D). On the first day of the course, students completed a background form in which they self-reported their visual art talent according to the scale (1 to 9) shown in Appendix 1.

Class lectures consisted of the instructor drawing with the same materials that the students used (wooden \#2 pencil and blank $81 / 2 \times 11$ in. paper), with his drawings projected on a screen with a digital camera/projector. For every drawing, the instructor started with a lightly drawn square (2D) or cube (3D) to show how any object or shape can be drawn based on a square or cube. Students created drawings during each class session and were told not to erase the light construction lines in order to show the viewer how the drawing was developed. Students were assigned homework after classes 1 to 7, which typically consisted of drawing simple objects such as electrical or plumbing hardware with the methods discussed in class. Students reported that they spent an average of one hour to do two homework drawings. The contents of the ten class sessions are shown in Appendix 2.

\section{Assessment Results}

The median of students' self-reported visual art talent scores was 4 with a mean of $3.5(\mathrm{sd}=1.5)$. A score of 3.5 is between the verbal description for 3 (I can draw a geometric object in top/side/front views that sort of looks like the object; people can recognize the object) and 4 (I can draw a geometric object in $3 D$ (isometric or oblique) that sort of looks like the object; people can recognize the object).

The course was assessed with evaluations of drawings conducted by two outside reviewers, who are veteran industrial designer who have worked with engineers for more than 30 years each. Two sets of drawings from each student were evaluated:

- Each student's sketch of a pipe fitting that was drawn in the first class (pre-test) and a sketch of the same pipe fitting in the eighth class (after >7 hours of instruction-post-test). Two outside reviewers rated each drawing on a scale from 1 (poor) to 7 (excellent). Students had to complete each sketch in less than $25 \mathrm{~min}$. The reviewers did not know the name of the student or whether each drawing was pre- or post-test during evaluation. Figure 1 shows one student's pre- and post-test sketches of the pipe fitting. 
- The final projects, which were a collection of five sketches with different views of an engineered product. Figures 2 to 6 show an example of one final project. Students spent an average of one hour drawing each page of the final project. Both reviewers rated each final project on a scale from 1 (poor) to 7 (excellent).

As indicated in Figures 7 and 8, Reviewer 1 rated the second drawing of the pipe fitting with a median score of 1 point higher than the first drawing (mean $=0.9, \mathrm{sd}=1.44$ ), and Reviewer 2 rated the second drawing with a median of 0.5 points higher (mean $=0.55, \mathrm{sd}=1.40$ ). The average difference between pre- and post-test drawings for Reviewer 1 was significantly different than zero $(\mathrm{p}=0.005)$ but the average difference for Reviewer 2 was not $(\mathrm{p}=0.346)$. Reviewer 1 rated the final projects with a median score of $7(\mathrm{sd}=1.23)$, and the median score from Reviewer 2 was 4 (sd=1.65), as shown in Figure 9.

\section{Discussion}

The assessment methods were intended to test the short-term goal of this project, namely to improve the freehand sketching ability of engineering students, and not the long-term desired learning outcome (to enhance the creativity and innovation of engineering design projects). Assessment of the desired learning outcome would require at least two or more years of study comparing students who have taken the course to a cohort of students who have not taken the course. Thus it is not possible to compare results of this course to those reported in the literature that revealed the benefit of freehand sketching to design outcome. ${ }^{4,5}$ For this reason, this discussion will pertain only to the short-term goal of the course.

The average difference between the evaluations from Reviewer 1 of the pre- and post-test drawings was 0.9 , which was statistically significant and appears to be a practical difference, given the short time span between the first and eighth classes ( $3 \frac{1}{2} 2$ weeks). However, the evaluations from Reviewer 2 did not show a significant difference. Thus, based on Reviewer 2's lack of a significant difference between pre- and post-test assessment data, one cannot conclude that this course achieved the short-term goal of improving the freehand sketching ability of engineering students.

The final project scores were very high from Reviewer 1 (median $=7$ ) and moderate from Reviewer 2 (median=4). This difference may have been due to varying expectations of the reviewers, who are industrial designers who have worked with engineers for over 30 years each. Each reviewer was told a priori to evaluate the drawings based on the expectations of the drawing skills of engineers, not industrial designers.

The instructor showed several of the final projects to faculty colleagues in the College of Engineering, and the responses were overwhelmingly complimentary. Several faculty said that they look forward to having these students in future classes because it would be easier to teach them not only design, but also dynamics and other course content that requires freehand sketches, such as free body diagrams.

The literature has shown that freehand sketching is "visual thinking" and is a necessary part of the design process for engineers. ${ }^{1}$ The seminal Grinter Report emphasized the importance of 
graphical expression for engineers, including sketching, as a means for creative thinking, spatial visualization, and the ability to convey ideas. ${ }^{6}$ However, freehand sketching has not been taught generally in engineering curricula in the U.S. in the last 20 years because of the prevalence of CAD software. It is important to distinguish between the purpose of freehand sketching and CAD software, as these two methods do not compete but complement each other. Freehand sketching is intended only for the concept and generation stage of design, while CAD is useful for working out the details of a design. In the freehand sketching course, the instructor intentionally did not use any instrument other than a pencil to avoid the comparison between manual drawing with mechanical instruments (similar to mechanical drafting before the 1990s) and CAD. The focus of the course was to teach students how to sketch anywhere with only a writing instrument and a surface, whether it is stationery paper, engineering paper with grid lines, backs of envelopes, or paper table cloths in restaurants. Design ideas can emerge at any time, and it is important to record those ideas, regardless of the limitations of the place.

This course should be assessed more rigorously in the future to determine if it meets the specific short-term goal of improving freehand sketching ability and the desired long-term learning outcome of improving the quality of design outcomes. Potential improvements in the assessment methods include:

- Use of three or more reviewers to evaluate drawings using a scoring rubric. The use of two reviewers in this study resulted in large variation between the two reviewers' scores of pre- and post-test drawings and final projects, making it difficult to draw any useful conclusions regarding the effect of the course on the sketching abilities of engineering students. The third reviewer should be an engineer with extensive sketching experience and who is very familiar with sketches of other engineers.

- Pipe fitting sketches created at the beginning, middle, and end of the course. This will provide data to allow for three points of evaluation during the course which will show whether the rate of improvement (or lack of) changes during the first or second half of the course.

- Assessment of students' spatial ability at the beginning of the class. A possible metric would be the 3D cube test that Schutze et. al. ${ }^{4}$ used at the beginning of their study to measure spatial ability of students.

- Increased number of students in the course. A larger sample size will help enhance the generalizability of the results to the engineering student population as well as increase the statistical power of analysis.

- Use of graphical plots that show whether students with greater visual art talent (at the beginning of the course) improve (or degrade) their sketching ability at a different rate than students who have lower visual art talent. This could help test the hypothesis that students with a lower level of talent would improve more than those with a higher level of talent. The sample size of 22 from the original class does not provide sufficient statistical power to test this hypothesis.

- Comparison of final project sketches to sketches created by students who did not take the course. This will provide a control group to which comparisons can be made. 


\section{Conclusion}

Assessment results suggest that this course has the potential to improve a student's ability to sketch objects, based on comparisons of pre- and post-test drawings and evaluations of final projects by outside reviewers. Feedback included a statistically significant and practical improvement of the scores of pre- and post-test drawings from one reviewer and positive observations by faculty colleagues. However, the course needs to be assessed more rigorously. When the course is repeated, more assessment measures described in this paper should be implemented. Future assessment data will be combined with data from the original course to determine if the course meets its short-term goal to improve freehand sketching ability of engineering students. Assessment of the long-term desired learning outcome to enhance the creativity and innovation of engineering student design projects will require additional time and effort.

\section{References}

1. Sorby, S.A. (2009). Educational research in developing 3D spatial skills for engineering students. International Journal of Science Education. Vol. 31, No. 3, Feb. 1, 2009, pp 459-480.

2. Ullman, D., Wood, S., and Craig, D. (1990). The importance of drawing in the mechanical design process. Computation and Graphics, Vol. 14, No. 2, 263-274.3.

3. Ferguson, E.S. (1922). Engineering and the Mind's Eye. Cambridge, MA: MIT Press.

4. Schutze, M., Sachse, P., and Romer, A. (2003). Support value of sketching in the design process. Research in Engineering Design. Vol. 14, 89-97.

5. Yang, M. (2009). Observations on concept generation and sketching in engineering design. Research in Engineering Design. Vol. 20, 1-11.6.

6. ASEE (American Society for Engineering Education) (1955). Report of the committee on evaluation of engineering education. Journal of Engineering Education, Vol. 46, 25-60.

7. Prince, M, "Does Active Learning Work? A Review of the Research," Journal of Engineering Education, Vol. 93, No. 3, pp. 223-231.

8. Goldberg, J. and Nagurka, M. "Enhancing the Engineering Curriculum: Defining Discovery Learning at Marquette University," Proceedings of the 2012 Frontiers in Education Conference (CD ROM). Presented at the 2012 Frontiers in Education Conference, Seattle, WA, Oct. 2012.

\section{Acknowledgements}

The authors would like to thank Dean Robert Bishop of the Marquette University College of Engineering and the Lafferty family for supporting this project as part of a college-wide effort to increase the level of student-centered learning in the College of Engineering. 


\section{Appendix 1: Likert scale for self-reported descriptions of visual art talent.}

\begin{tabular}{|l|l|}
\hline 1 & I have absolutely no talent; I cannot even draw a stick figure well. \\
\hline 2 & I can draw a stick figure pretty well, but not anything more than that. \\
\hline 3 & $\begin{array}{l}\text { I can draw a geometric object in top/side/front views that sort of looks like the object; } \\
\text { people can recognize the object. }\end{array}$ \\
\hline 4 & $\begin{array}{l}\text { I can draw a geometric object in 3D (isometric or oblique) that sort of looks like the object; } \\
\text { people can recognize the object. }\end{array}$ \\
\hline 5 & $\begin{array}{l}\text { I can draw a geometric object well in top/side/front views and in 3D (isometric or oblique, } \\
\text { but not perspective); people can easily recognize the object. }\end{array}$ \\
\hline 6 & $\begin{array}{l}\text { I can draw and shade a geometric object well in top/side/front views and 3D (isometric or } \\
\text { oblique); people can easily recognize the object, and they say "you can draw pretty well." }\end{array}$ \\
\hline 7 & $\begin{array}{l}\text { I can draw and shade an object with curves (like a shoe or car) well in top/side/front views } \\
\text { and perspective (including isometric or oblique); people can easily recognize the object, } \\
\text { and they say “you can draw really well." }\end{array}$ \\
\hline 8 & $\begin{array}{l}\text { People say that I have enough talent to be a visual artist and possibly have a career in } \\
\text { visual art. }\end{array}$ \\
\hline 9 & \begin{tabular}{l} 
I can draw objects and buildings as well as Frank Lloyd Wright did. \\
\hline
\end{tabular} \\
\hline
\end{tabular}




\section{Appendix 2: Description of activities in the ten classes}

1. Draw the plastic pipe fitting in $<25 \mathrm{~min}$ (pre-test drawing); how to hold a pencil; draw lines of various weights; rotate paper so minimize angular deviation of the wrist; draw orthographic views of a cube (top, side, front)

2. Collect homework; review orthographic views of a cube; draw a circle with the 8-point method; draw orthographic views of a metal electrical box

3. Collect homework; review orthographic views of electrical box; draw isometric view of a cube; draw ellipses using the 8-point method

4. Collect homework; review circles and ellipses; draw electric box with isometric view

5. Collect homework; review isometric; draw cube with front oblique; draw circles and ellipses in front oblique; draw electric box in front oblique

6. Collect homework; review front oblique; draw cube with plan oblique; draw circles and ellipses in plan oblique; draw electric box in plan oblique

7. Collect homework; review plan oblique; introduce final project, which is a collection of five sheets of drawings of an engineered product (different views); review all drawing methods

8. Collect homework; draw the plastic pipe fitting in $<25 \mathrm{~min}$ (post-test drawing); discuss final project ideas with each student; work on final project in class

9. Discuss final project ideas with each student; work on final project in class

10. Turn in final project (min 5 pages of drawings) 


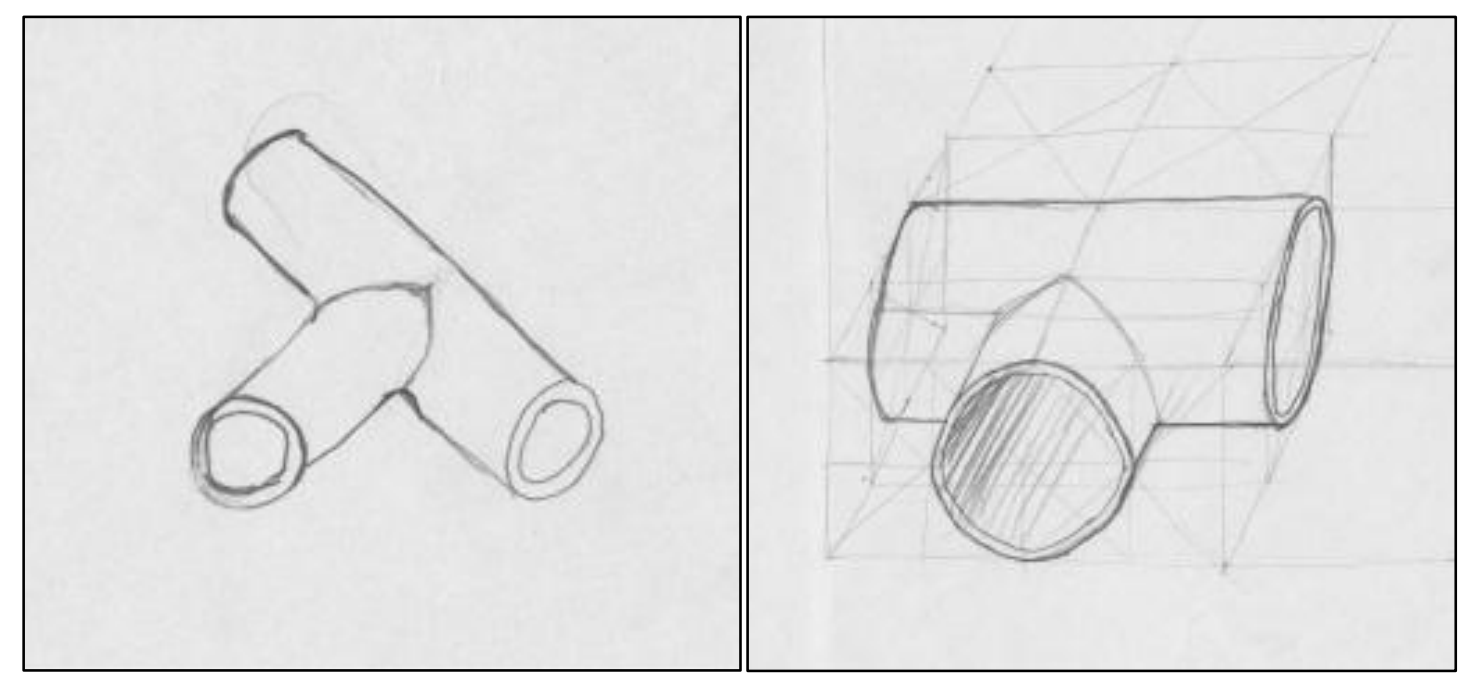

Figure 1. One student's pre-test (left) and post-test (right) sketch of a plastic pipe fitting. The pre- and post-test sketches were drawn in the first and eighth classes, respectively.

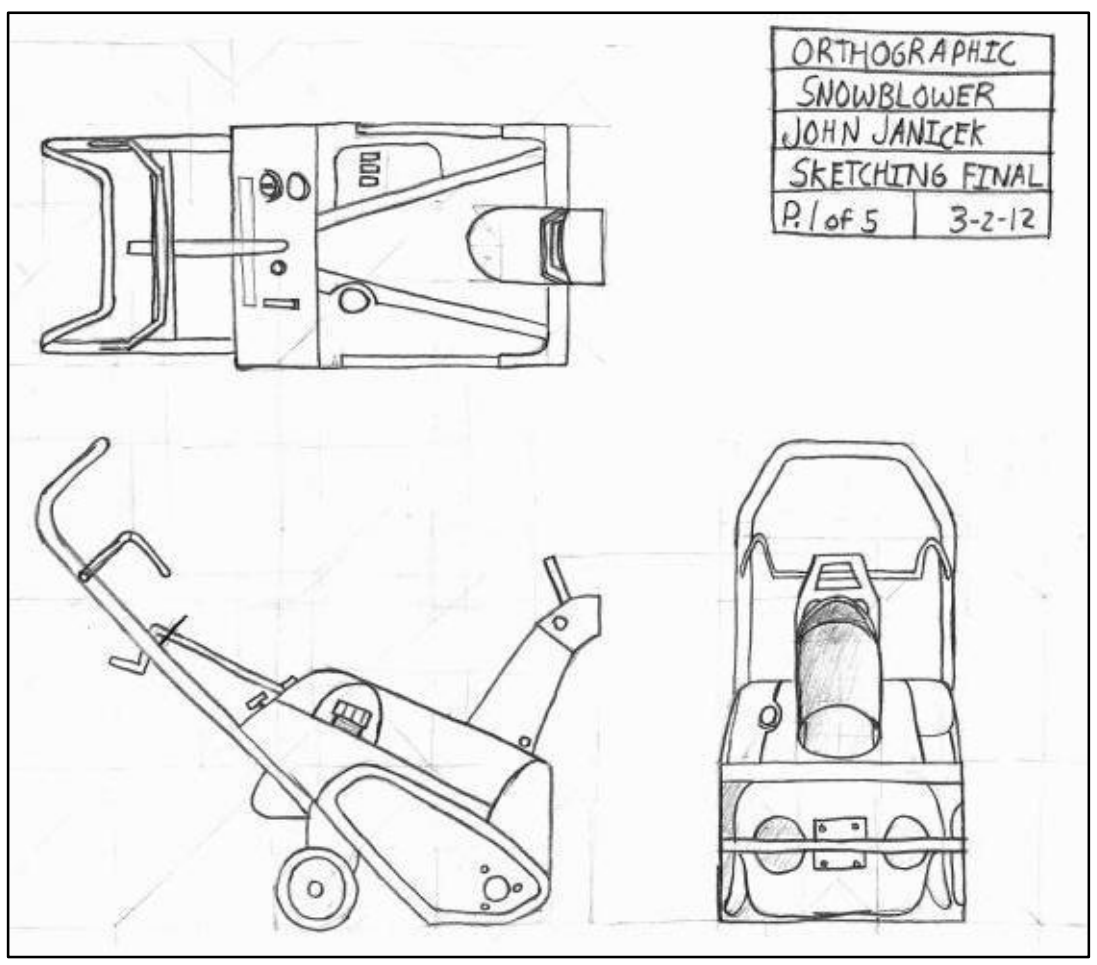

Figure 2. Example of one student's final project. Orthographic drawings of a snow blower. 


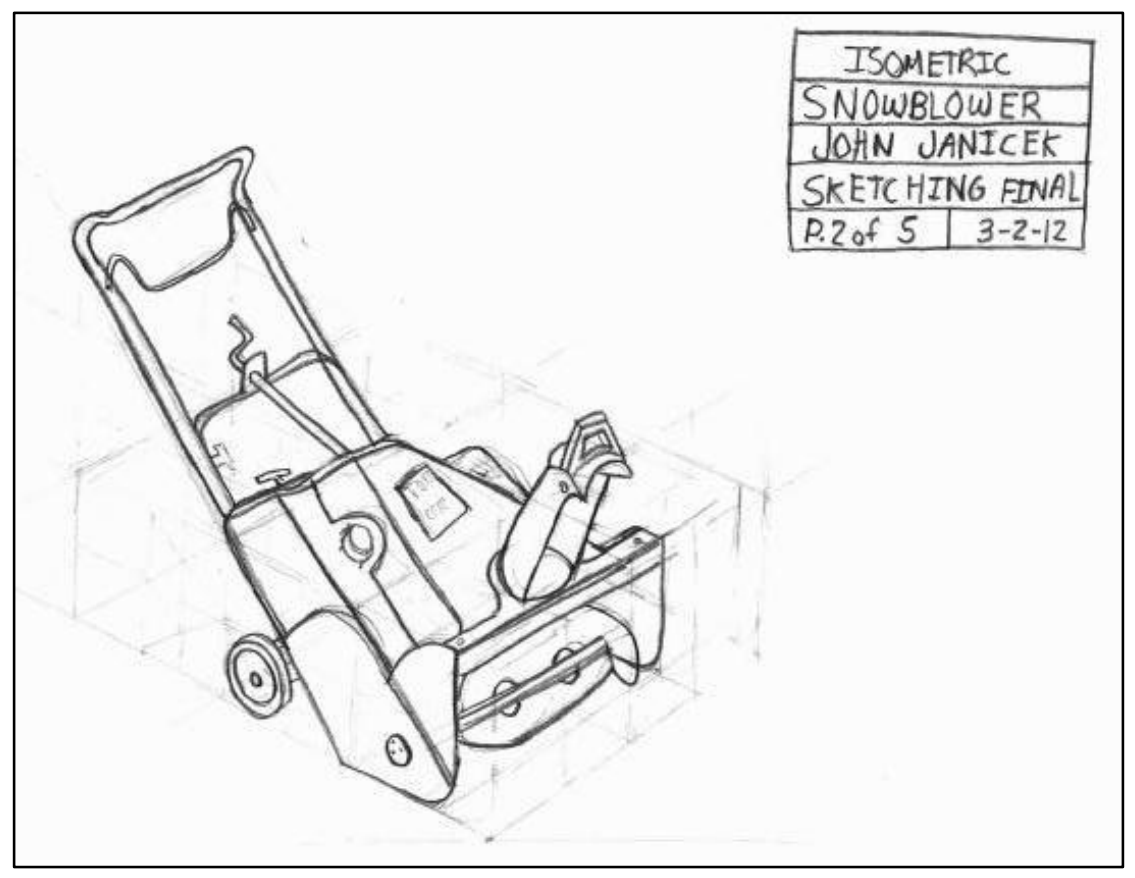

Figure 3. Example of one student's final project. Isometric drawing of a snow blower.

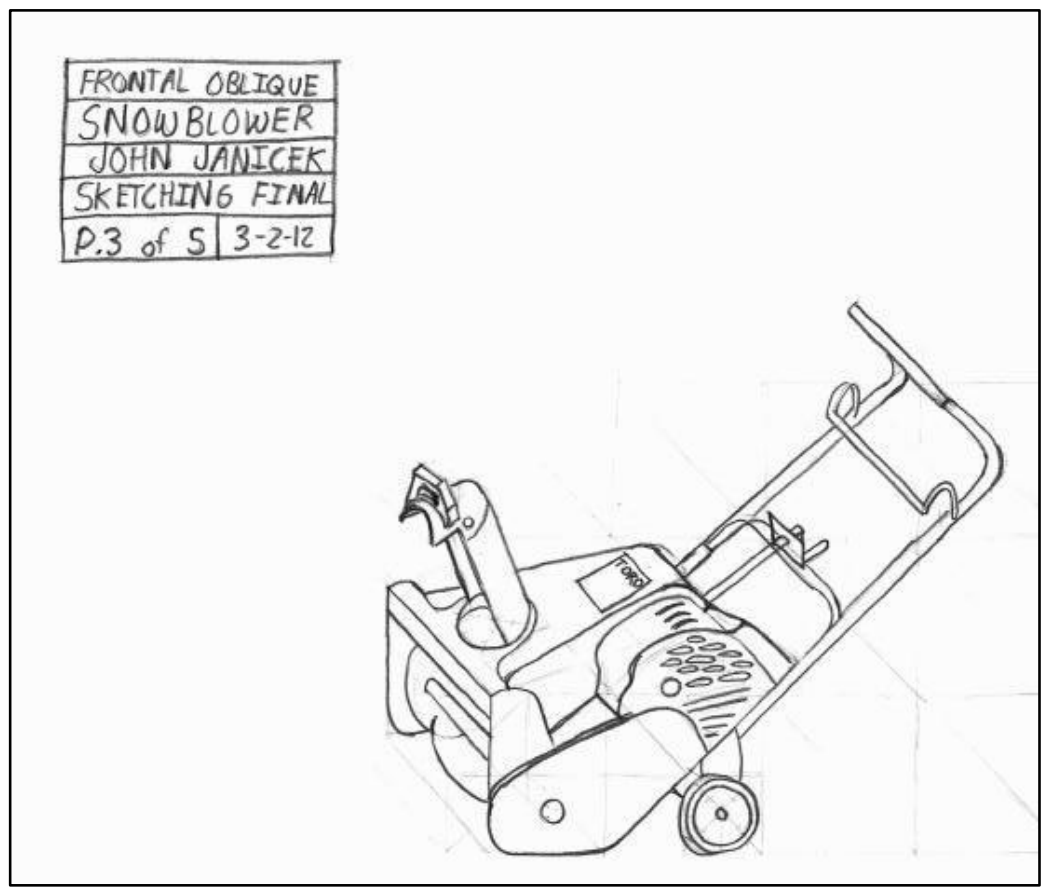

Figure 4. Example of one student's final project. Front oblique drawing of a snow blower. 


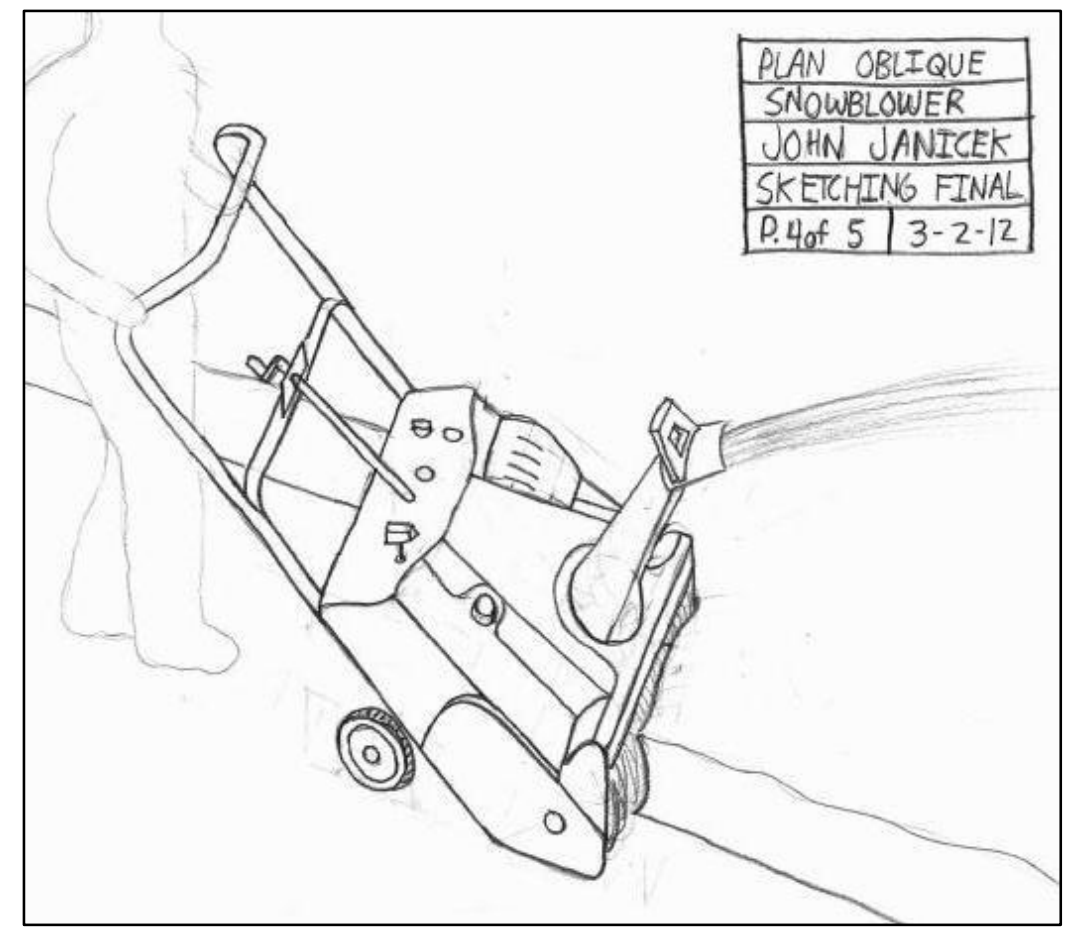

Figure 5. Example of one student's final project. Top (plan) oblique drawing of a snow blower.

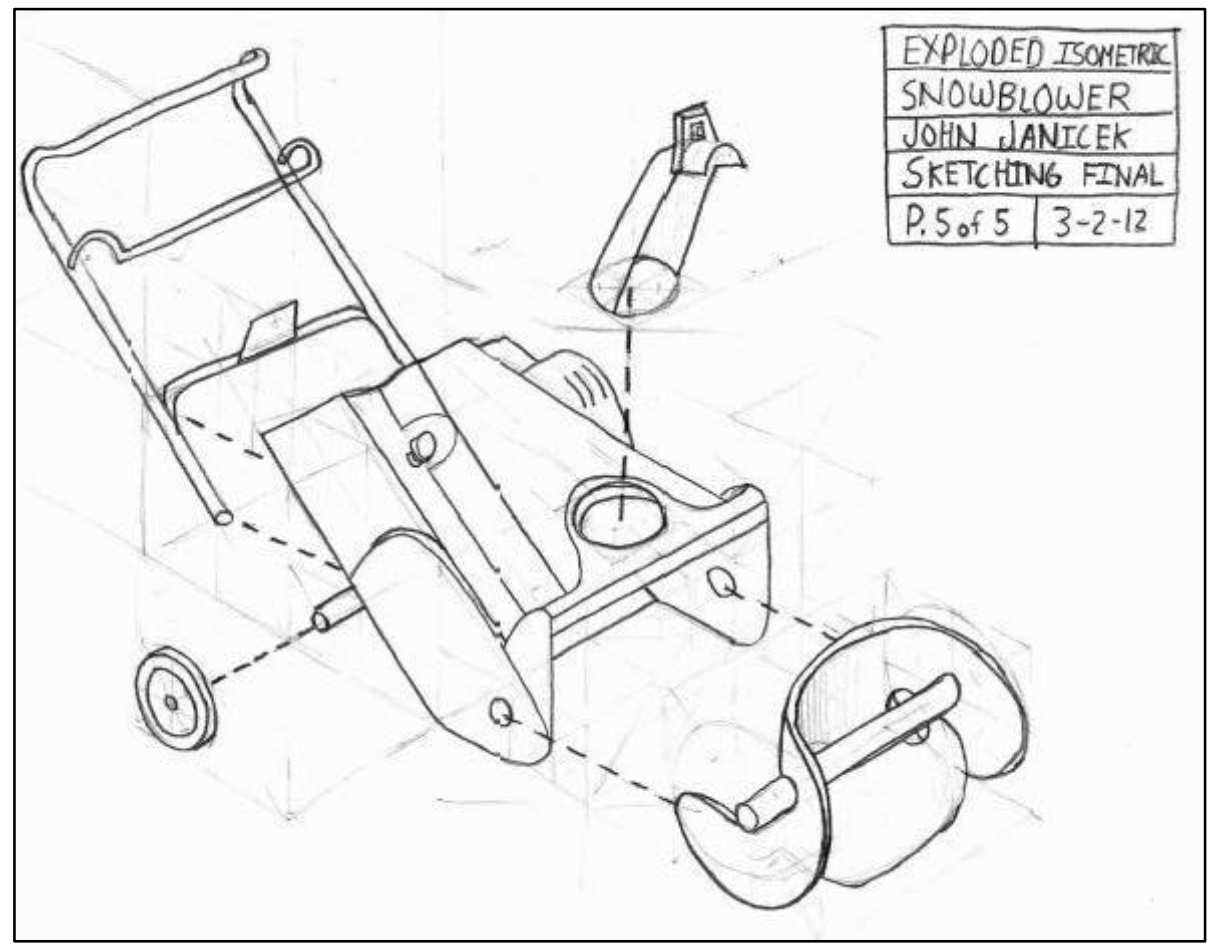

Figure 6. Example of one student's final project. Isometric drawing of parts and assembly of a snow blower. 


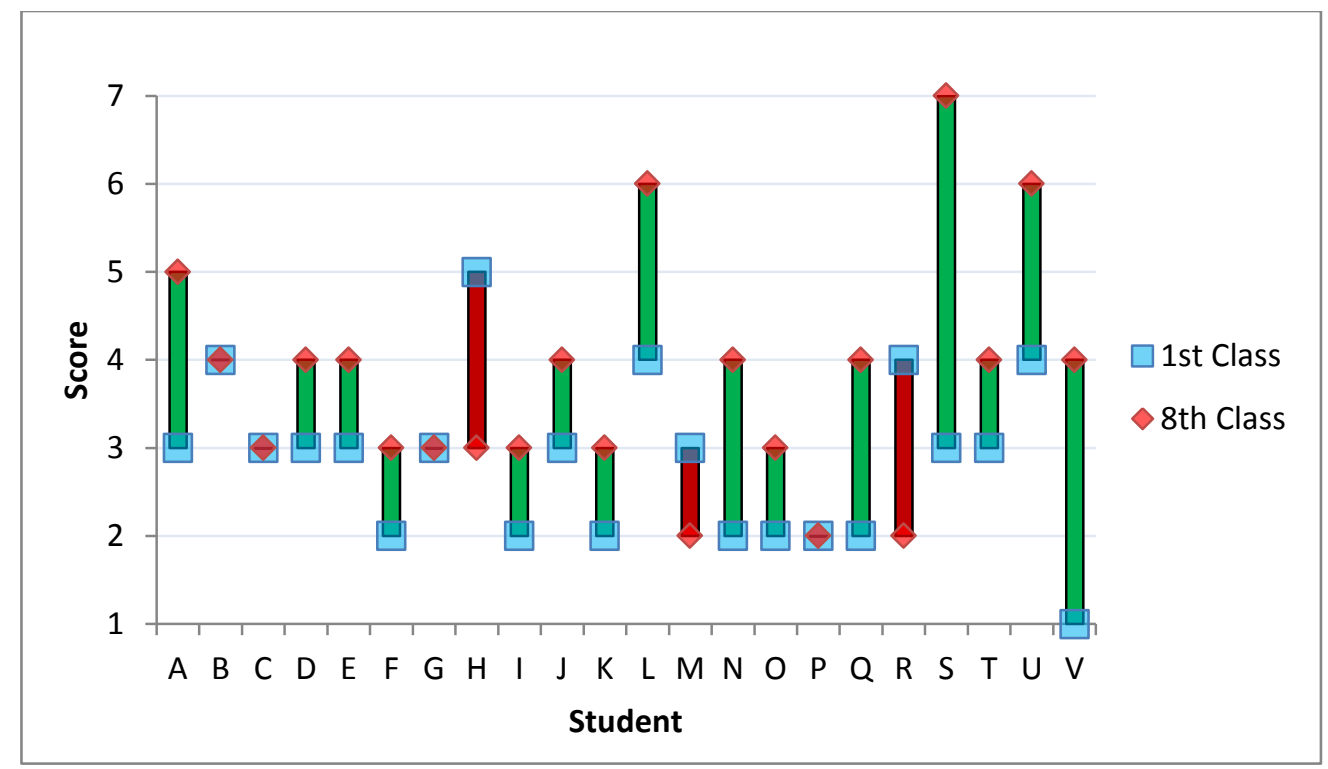

Figure 7. Reviewer 1 scores of the sketches of the pipe fitting drawn in the first and eighth classes ( $1=$ poor, $7=$ excellent). Scores for 15 students improved (green), 3 decreased (red), and 4 stayed the same.

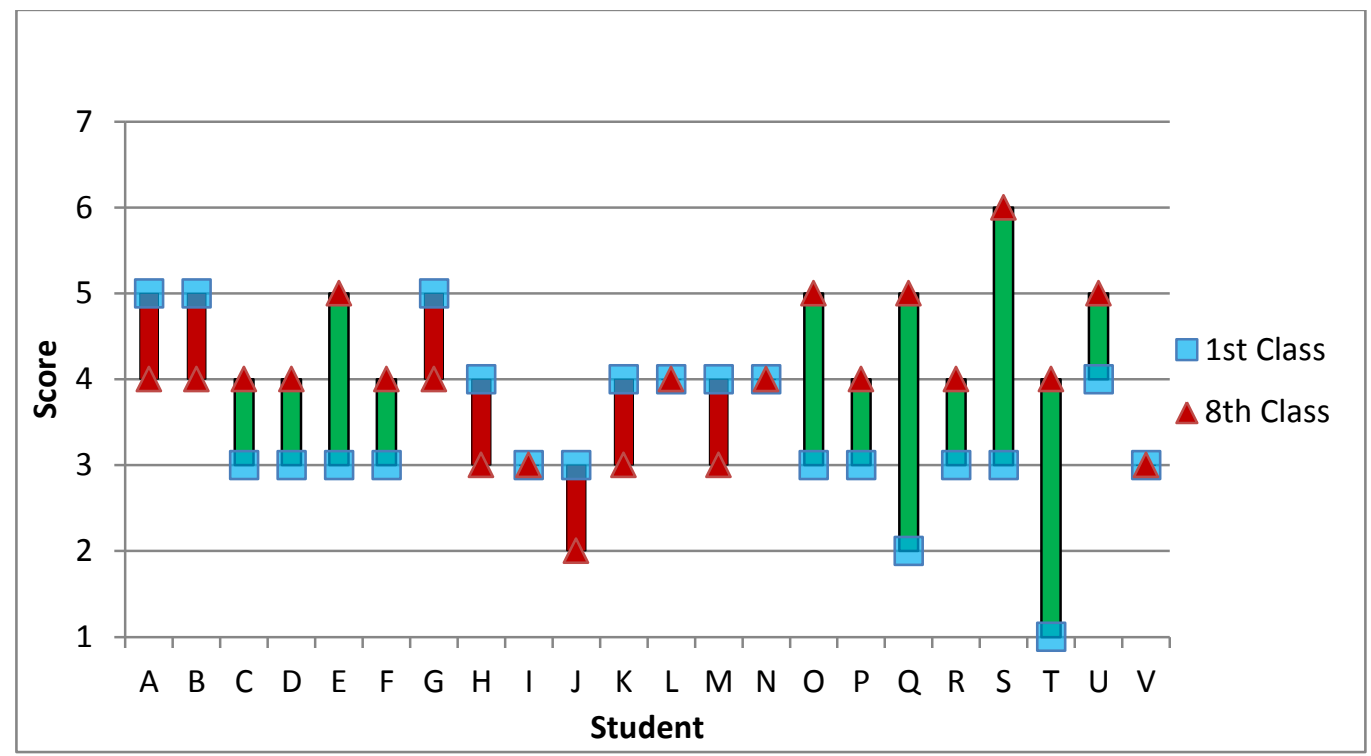

Figure 8. Reviewer 2 scores of the sketches of the pipe fitting drawn in the first and eighth classes (1= poor, $7=$ excellent). Scores for 11 students improved (green), 7 decreased (red), and 4 stayed the same. 


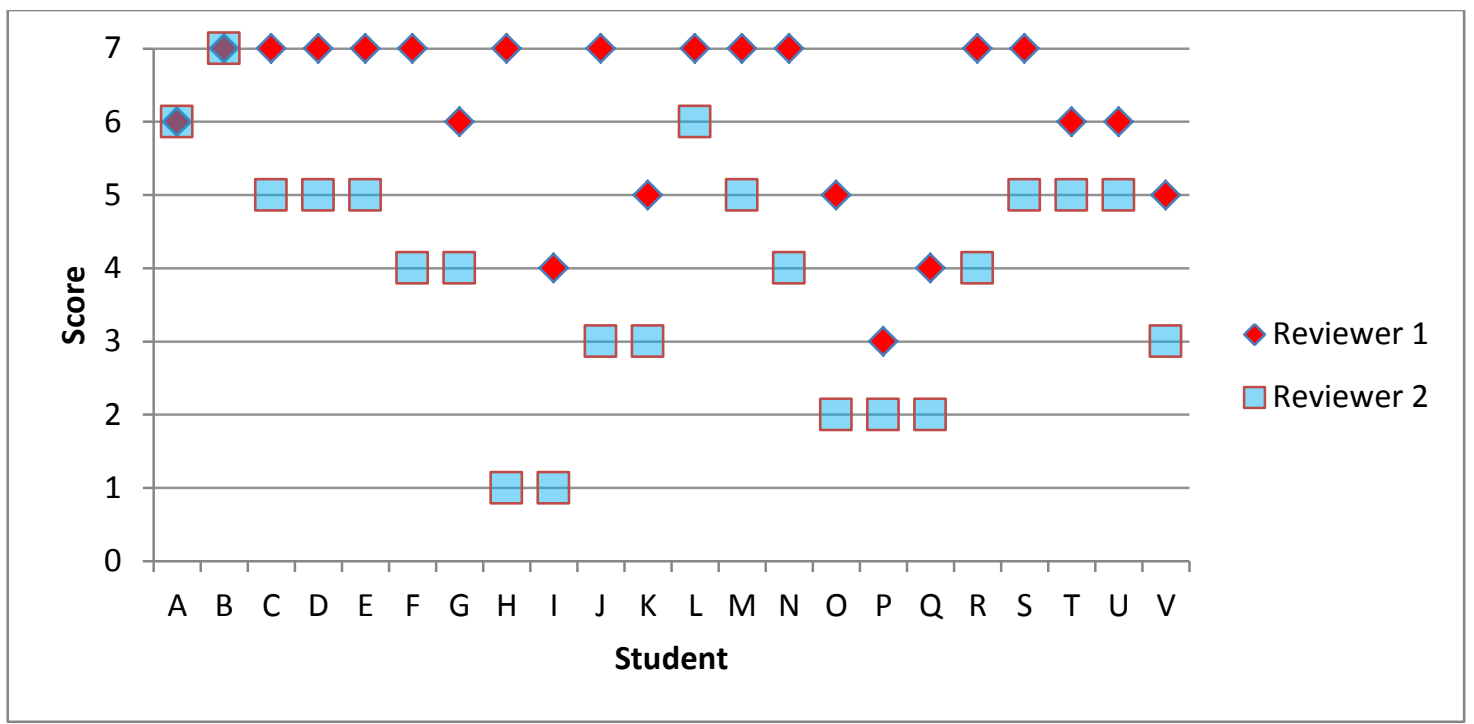

Figure 9. Reviewers 1 and 2 scores of the final projects (1=poor, 7=excellent). 